\title{
Peertechz
}

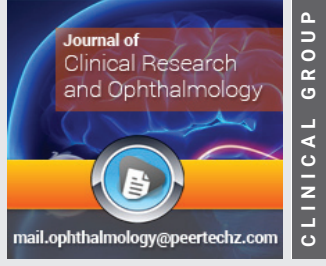

\section{Unusual increase in the incidence of unilateral Optic Neuritis: Case presentation}

\section{Odalys Cáceres-Toledo', María Cáceres-Toledo²*, Runse Zhao $^{3}$, Yeimi Carolina Laurencio ${ }^{3}$, Yarlín La O-Lozano ${ }^{4}$ and Irinia Díaz-Ríos ${ }^{4}$}

${ }^{1}$ Assistant Professor and Researcher, Second Degree Specialist in Ophthalmology and MGI, Hermanos Ameijeiras Clinical Surgical Hospital (HHA), Havana, Cuba

${ }^{2}$ Professor and Senior Researcher, Second Degree Specialist in Ophthalmology. Doctor of Medical Sciences, Hermanos Ameijeiras Clinical Surgical Hospital (HHA), Havana, Cuba

${ }^{3}$ First Degree Specialist in Ophthalmology, Hermanos Ameijeiras Clinical Surgical Hospital (HHA) Havana, Cuba

${ }^{4}$ Degree in Optics and optometry, Hermanos Ameijeiras Clinical Surgical Hospital (HHA), Havana, Cuba

ORCIDs:

*Odalys Cáceres-Toledo: https://orcid.org/0000-0003-1791-432X

María Cáceres-Toledo: https://orcid.org/0000-0003-3606-4535

Runse Zhao: https://orcid.org/0000-0002-1206-1623

Yeimi Carolina Laurencio: https://orcid.org/0000-0003-4590-441X

Yarlín La O-Lozano: https://orcid.org/0000-0003-2346-1742

Irinia Díaz-Ríos: https://orcid.org/0000-0003-3506-1260
Received: 16 September, 2021

Accepted: 27 September, 2021

Published: 28 September, 2021

*Corresponding authors: María Cáceres-Toledo, Professor and Senior Researcher, Second Degree Specialist in Ophthalmology. Doctor of Medical Sciences, Hermanos Ameijeiras Clinical Surgical Hospital (HHA), Havana, Cuba, E-mail: alvaca@infomed.sld.cu Mariacaceres2204@gmail.com

Keywords: Optic neuritis; Increased incidence; Time of evolution; OCT

Copyright: ( 2021 Cáceres-Toledo 0, et al. This is an open-access article distributed under the terms of the Creative Commons Attribution License, which permits unrestricted use, distribution, and reproduction in any medium, provided the original author and source are credited

https://www.peertechzpublications.com

\section{Check for updates}

\section{Abstract}

Optic neuritis presents as an acute or subacute inflammatory episode.

Objective: Describe the clinical-epidemiological characteristics in 7 cases with unilateral optic neuritis and evaluate the therapeutic results obtained.

Material and method: A series of cases with a diagnosis of unilateral optic neuritis who attended the Neurophthalmology consultation at the Hermanos Ameijeiras Hospital in Havana, Cuba, from August 6 to November 16, 2018, from Havana and Matanzas, were studied. An unusual increase in the incidence of NO was recorded in the period analyzed.

Results: An unusual increase in the incidence of unilateral optic neuritis was recorded. The average age was 33.5 years. All reported unilateral painless visual loss. Four patients reported general signs and symptoms suggestive of having suffered a respiratory disease of viral origin, between 7 and 15 days before optic neuritis. In the examination carried out, great impairment of visual acuity $(\leq 0.05)$ and colors $(0 / 21)$ was found. The centro-caecal scotoma was the most frequent campimetric defect. Optical Coherence Tomography (OCT) in the affected eye showed increased neuroretinal thickness, decreased nerve fiber layer, and ganglion cell damage. Treatment was with intravenous methylprednisolone and B vitamins.

Conclusions: An unusual increase in patients with unilateral optic neuritis was observed. The OCT revealed damage to the structures at the level of the retina and the optic nerve. The therapeutic effectiveness was conditioned by the time of evolution of the neuritis.

\section{Introduction}

Optic Neuritis (NO) is an acute or subacute inflammatory process, with visual loss. It can affect one or both eyes. In most cases, visual acuity recovers within two weeks. However, in some the visual deficit may be permanent [1-8].

Although the exact pathogenesis of NO is unknown, it is assumed that it involves a delayed type IV hypersensitivity 
reaction in which peripheral $\mathrm{T}$ lymphocytes are activated [6-10]. Due to its etiology, it is classified as: idiopathic, demyelinating, parainfectious, for perinasal sinus sepsis, meningitis, cat scratch fever (caused by Bartonella henselae), and associated with systemic autoimmune diseases [9-12].

The term NO is broad and is generally associated with the typical variant of Multiple Sclerosis (MS) and the spectrum of conditions that occur in neuromyelitis optica or Neuromyelitis Optica Spectrum Disorder (NMOSD), for its acronym in English language [1-3]. These diseases are autoimmune and are characterized by inflammation, demyelination, and axonal damage [7]. Antibodies against astrocyte water channels (AQP4 or Aquaporin-4) are involved in NMOSD [3].

Atypical NO is defined as inflammation of the optic nerve not associated with MS. Its characteristics are the absence of periocular pain, a non-typical age of onset (under 15 years and over 50) or the absence of visual improvement after two weeks of treatment $[2,3]$.

In 2010, the Brazilian Marrocos de Aragão [13] raised the parainfectious etiology in two cases with NO and a history of having suffered dengue between 7 and 10 days before. According to Sanjay, the first report of parainfectious NO related to dengue was made in China in 1989. [14].

Since 1999, Zhu [7] has shown that demyelination always occurs in NO, depending on its clinical severity, but irreversible damage to the axonal skeleton occurs between 5 and 7 days. In Shindler's experimental studies [8] inflammation precedes demyelination and axonal degeneration by two days, so the time for successful treatment is short.

The worldwide incidence of unilateral NO is $0.94-2.18$ per 100,000 [5]. Its incidence in Cuba is not known.

In 2018, the unusual attendance of several cases with unilateral acute NO was observed at the Neurophthalmology consultation of the "Hermanos Ameijeiras" Clinical Surgical Hospital (HHA) in Havana, Cuba in a short period of three months.

A series of cases with unilateral optic neuritis is presented, with the objective of describing its clinical-epidemiological characteristics and evaluating the therapeutic results and their relationship with the time of evolution of the disease.

\section{Methodology}

A total of 7 cases were studied ( 4 men and 3 women), who consecutively attended the Neurophthalmology consultation of the HHA, referred by the ophthalmologists of their respective health areas from August 6 to November 16, 2018, from sudden painless loss of vision in one of your eyes. All were hospitalized for study and treatment.

\section{Neurophthalmological studies}

Best Corrected Visual Acuity (BCVA) It was performed with an autorefractometer (Nidek-casa Aichi, Japan), which has a projector with Snellen's visual chart.
Study of pupillary reflexes. It was performed with the Fy Oph-259 ophthalmoscope (Fujiyama, Japan). They were classified as normal, affected or absent.

Color Vision study (CV) It was carried out with the Ishihara test. 21 slides were examined. Those that the patient reads in the test are placed in the numerator and the 21 examined in the denominator. The normal value is $21 / 21$.

Fundoscopy of the retina and optic nerve. It was done with the ophthalmoscope. It was considered as. Normal: no abnormalities are observed. Pathological: Neuroretinitis (NR); edema of the papilla and retina with deposits of inflammatory cells is observed. Retrobulbar neuritis (NRB): in this, no alterations are observed in the initial stage, because the involvement is in the posterior or retrobulbar portion of the nerve.

\section{Diagnostic means}

Static Perimetry (PE) It was performed with the Optopus perimeter (Haag-Streit, Germany). This test may be normal or a central scotoma may appear, if it only affects between 5 and 10 degrees of the visual field (CV); ceco-central, if it is also affected from the blind spot or blind spot to the center; and altitudinal, if the scotoma takes an upper or lower quadrant of the CV.

Optical coherence tomography of the papilla and macula (OCT) It was performed with the Cirrus HD 5000 tomograph (Carl Zeiss, Germany). A study was made of the papilla or head of the optic nerve and the macula. The team offers a normative database for each person of the same age and sex.

Neurological examination. This test was added to the systemic study of the patient, aimed at detecting possible alterations associated with demyelinating diseases. Lumbar puncture and cytological and immunological analysis of Cerebrospinal Fluid (CSF) were performed. In cases with suspected MS, high-field Magnetic Resonance Imaging (MRI) of the skull and cervical region was indicated.

Treatment It was carried out according to the HHA protocol [15]. Steroid treatment with methylprednisolone (AICA Laboratories, Cuba), $500 \mathrm{mg}$ bulbs was used. The therapeutic scheme consisted of a pulse of $1 \mathrm{~g}$ of methylprednisolone (2 bulbs of $500 \mathrm{mg}$ ) dissolved in $0.9 \%$ balanced saline solution (Laboratorios AICA, Cuba), applied intravenously, lasting 4 hours, for three days, with rest of a day and an application of another pulse, depending on the response of the patient to the first. One or two pulses of this drug were used, for a total of 6 g. If with the first steroid pulse the patient improved the visual parameters measured before treatment, it was not necessary to repeat the second. The therapeutic scheme could be repeated up to a maximum of $12 \mathrm{~g}$ (four pulses). Each patient underwent a glycemic profile and blood pressure check during steroid treatment.

The same day, after the application of steroids, B complex vitamins (Laboratorios AICA, Cuba) were used intravenously, with application for one hour. The scheme was as follows: a vial 
of vitamins B1, B2 and B6 (10 mg of thiamine or B1, $1.5 \mathrm{mg}$ of riboflavin or $\mathrm{B} 2$ and $3 \mathrm{mg}$ of pyridoxine or $\mathrm{B} 6$ ), plus $1 \mathrm{~mL}$ of $\mathrm{B} 12$ (Laboratorios AICA, Cuba). Vitamin B12 or hydroxycobalamin is $1000 \mu \mathrm{g} / \mathrm{mL}$ in $5 \mathrm{~mL}$ bulbs.

Given the suspicion of a bacterial infection by Bartonella henselae, in the case of patient 1 (Table 1), ciprofloxacin, 250 $\mathrm{mg}$ and cotrimoxazole, $400 \mathrm{mg}$ (tablets, both from Medsol Laboratories, Cuba) were added to the treatment, orally, every 12 hours, for a week.

The treatment was considered satisfactory if, 15 days after its conclusion, the patients obtained improvement of at least 2 lines of the Snellen visual chart. It is known that CV recovers after VA in most cases3, so it was not taken into account to evaluate the initial therapeutic results.

Ethical aspects The treatment established by the HHA care protocol was applied. 15 Patients gave their written informed consent for the results of their studies to be used for research purposes. Anonymity about his illness was maintained in the processing and analysis of the data.

\section{Results}

Table 1 shows the sociodemographic data of the patients, the examinations performed and the evaluation of the treatment results. In the series, young adults predominated (mean 33.5 years; interval 23-44 years), with severe involvement of the BCVA, VC and scotomas in the CV.

The symptoms and signs reported by the patients were: sudden and painless loss of vision, which affected the central and / or lower part of the visual field, in addition to the deficit in color vision. Afferent pupillary defect was detected in all cases, due to unilateral involvement.

From 15 to 30 days before visual loss, $70 \%$ of the patients (5/7) reported symptoms and signs suggestive of a respiratory condition of viral origin. (Headache, arthralgias, asthenia general malaise) Three patients were referred from the Ciénaga de Zapata (Matanzas province) at the time of the increase in mosquitoes in that geographic area.
In the interrogation it was found that patient number 1 , resident in a rural environment, who cared for poultry animals (poultry and small livestock); she reported fever and arthralgias 15 days before the visual loss. In fundoscopy, disc edema and deposits in the macular region that formed a star were observed, due to the anatomical arrangement of the nerve fiber layer of the retina at that level (macular star).

Figure 1a shows the OCT performed on the patient, where the broken lines show the increase in the thickness of the neuroretinal border and the retinal fiber layer (RNFL), due to edema. No signs of infection were found in the hematological study or in the CSF study. As previously noted, this patient also received antibiotic treatment for 7 days.

The fundus image of case 7, shown in Figure $1 \mathrm{~b}$, (also with neuroretinitis, but of the $\mathrm{RE}$ ), is similar to that observed in case 1 , but without the macular star.

Patient 5, from Jagüey Grande (Matanzas province), is type 1 diabetic and hypertensive; in addition, at that time, he suffered stress from his work and personal life. No alterations were observed in the optic nerve head or papilla, in the initial stages of the inflammatory process (Figure $2 \mathrm{a}$ ). The absence of edema and effacement of the disc are evidenced in Figure $2 b$, where the arrow indicates the region of the papilla with its central cup. The graph shows that both the RE (expressed in the curve of continuous lines) and the LE (in dashed lines) remain within the normative basis, which confirms that the damage is not in the papilla or in the retina, but in the retrobulbar portion of the optic nerve. Figure $2 \mathrm{c}$ shows the analysis of the Ganglion CellInternal Plexiform Complex (GCIPL), performed on the same patient. The arrow indicates the area studied by OCT, delimited by two horizontal lines. The analysis expresses the decrease in the mean values of the RE and its normality in LE.

The aforementioned was also observed in the OCT performed on patients 3 and 4 (RE and LE, respectively), who also presented NRB.

In the PE (with the Octopus) performed on the same day in patient 5 , a negative scotoma or lack of perception of stimuli

Table 1: Clinical and neurophysiology study. Patient'record.

\begin{tabular}{|c|c|c|c|c|c|c|c|c|c|c|c|c|}
\hline Caso No & Age & Sex & Diag. & From. & Evol. & BVARE & BVALE & CVRE & CVLE & EPRE & EPLE & $\mathbf{R}$ \\
\hline 1 & 26 & $\mathrm{~F}$ & NR & JG & 30 & 1.0 & $c / d$ & $21 / 21$ & $0 / 21$ & $\mathrm{~N}$ & EC & NS \\
\hline 2 & 28 & $M$ & NR & $\mathrm{HC}$ & 7 & 0.1 & 1.0 & $0 / 21$ & $21 / 21$ & EC & $\mathrm{N}$ & $S$ \\
\hline 3 & 40 & $\mathrm{~F}$ & NRB & $\mathrm{HC}$ & 7 & 1.0 & PL & $21 / 21$ & $0 / 21$ & $\mathrm{~N}$ & EC & $S$ \\
\hline 4 & 25 & $M$ & NRB & $\mathrm{HC}$ & 7 & PL & 1.0 & $0 / 21$ & $21 / 21$ & DA & $\mathrm{N}$ & $S$ \\
\hline 5 & 44 & $M$ & NRB & JG & 10 & $c / d$ & 1.0 & $0 / 21$ & $21 / 21$ & DA & $\mathrm{N}$ & NS \\
\hline 6 & 44 & $\mathrm{~F}$ & NRB & C & 30 & 0.1 & 1.0 & $0 / 21$ & $21 / 21$ & ECC & $\mathrm{N}$ & NS \\
\hline 7 & 23 & $M$ & NR & $J G$ & 7 & 0.05 & 1.0 & $0 / 21$ & $21 / 21$ & ECC & $\mathrm{N}$ & S \\
\hline
\end{tabular}

Diag: Diagnostic: NR: Neurorretinitis; RBN: Retrobulbar Neuritis

From: JG: Jagüey Grande y C, Cárdenas (Matanzas); HC: Havana City.

Evol: Evolution time

BVARE: Best Visual Acuity Right Eye; BVALE. Best Visual Acuity Left Eye, LP: Only Light Perception. c/f: Counting Finger

CVRE: Color Visión Rigth Eye; CVLE: Color Visión Left Eye.

EPRE: Estatic Perimetry Right Eye. EPLE: Estatic Perimetry Left Eye. N: Normal; CE: central Escotoma; CCE: Centro-Cecal Escotoma; AD: Altitudinal Defect

R: Therapeutic Result: S: Satisfactory; NS: No satisfactory

Citation: Cáceres-Toledo O, Cáceres-Toledo M, Zhao R, Laurencio YC, O-Lozano YL, et al. (2021) Unusual increase in the incidence of unilateral Optic Neuritis: Case presentation. J Clin Res Ophthalmol 8(2): 044-048. DOI: https://dx.doi.org/10.17352/2455-1414.000093 
of the entire lower hemifield was observed with capture of the central area, which explains the loss of vision. High-field Magnetic Resonance Imaging (MRI) revealed peri-ventricular

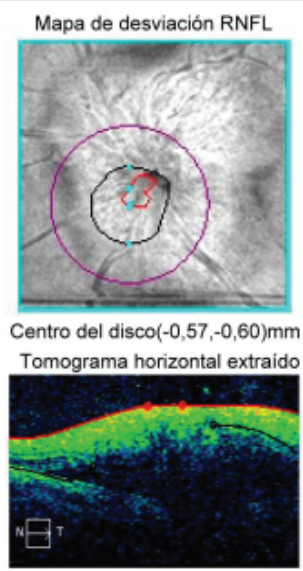

Tomograma vertical extraido
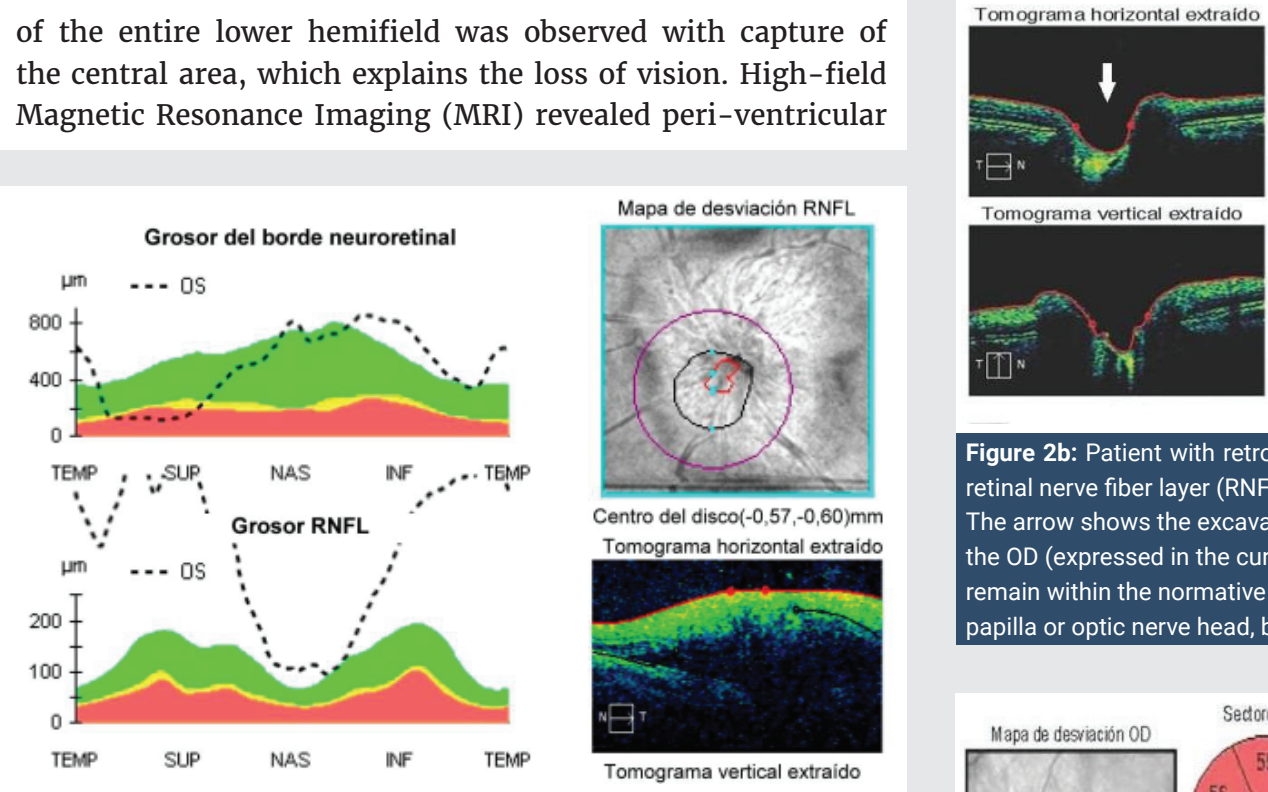

Tomograma vertical extraido
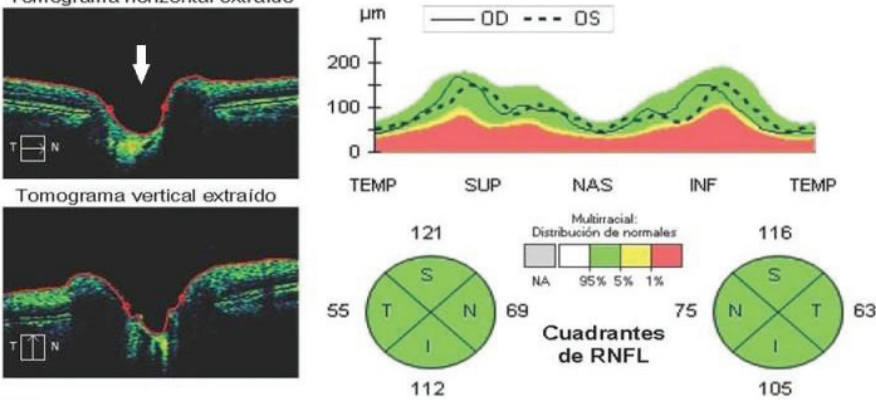

Figure $\mathbf{2 b}$ : Patient with retrobulbar neuritis (case 5). OCT the papilla. Study of the retinal nerve fiber layer (RNFL) of both eyes.

The arrow shows the excavation of the optic nerve. The graph shows that both the OD (expressed in the curve of continuous lines) and the OS (in dashed lines) remain within the normative base, which confirms that the damage is not in the papilla or optic nerve head, but in its retrobulbar portion.
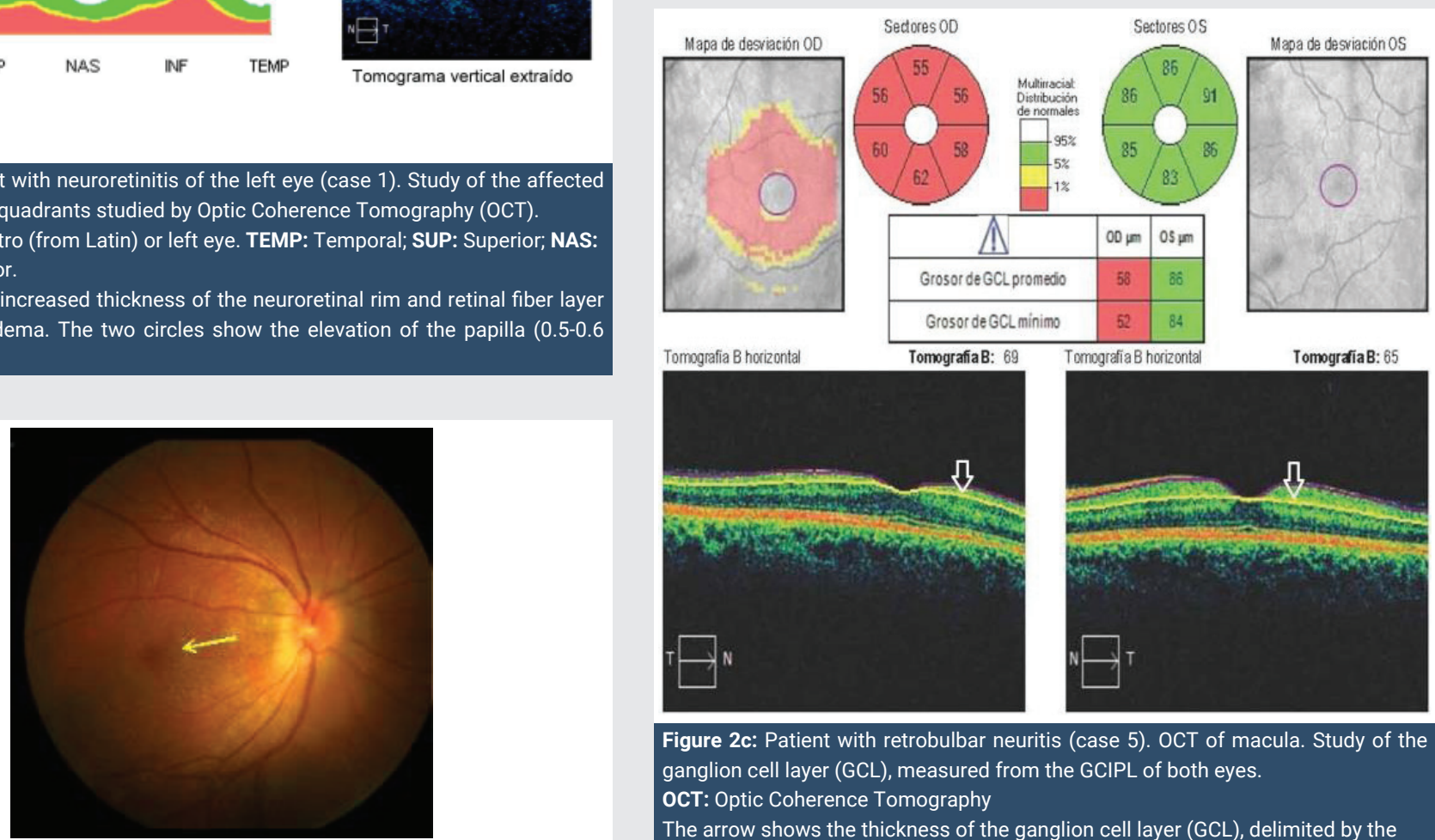

Figure 2c: Patient with retrobulbar neuritis (case 5). OCT of macula. Study of the ganglion cell layer (GCL), measured from the GCIPL of both eyes.

OCT: Optic Coherence Tomography

The arrow shows the thickness of the ganglion cell layer (GCL), delimited by the two lines. Its decrease is observed in the OD, which is expressed in all sectors of the circular scheme, as well as the mean values seen in the lower graph. In the OS everything is normal.

Red coloration of the papilla is observed. The borders are blurred due to edema and the acute inflammatory process extending into the retinal nerve fiber layer and reaching the macula. The arrow shows edema and exudates in the area called papillomacular bundle.

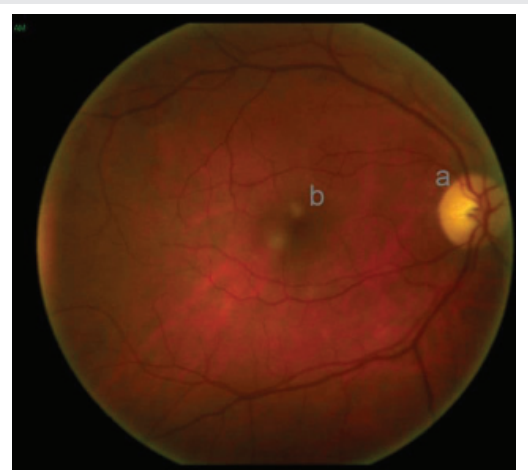

Figure 2a: Patient with retrobulbar neuritis in right eye del ojo derecho (caso 5). Fundoscopía.

Fundoscopía normal: a) papila o cabeza del nervio óptico; b) mácula. demyelinating plaques and / or vascular plaques; the one performed on the cervical spine was normal. In the CSF study, damage to the blood-brain barrier was detected, because the protein value was $95 \mathrm{mg}$ (normal value $20 \mathrm{mg}-40 \mathrm{mg}$ ); however, no oligocloal bands were detected, which denotes normality in this test. Based on the clinical development of this patient, the diagnostic possibility of NMOSD was raised, but specific studies are still lacking to confirm this clinical variant of MS.

The therapeutic results were satisfactory in four of the seven patients (cases 2, 3, 4 and 7), who were diagnosed and treated within 7 days of evolution of NO (57\% therapeutic effectiveness). These patients achieved normal vision (20/20) between one and two weeks after treatment and eliminated the 
scotoma of the CV. However, only 6 to 8 color plates improved on the Ishihara chart. In the remaining three (cases 1, 5 and 6 ) there were no changes in visual parameters after the same treatment, that is, there was no clinical improvement.

Patients 2, 4 and 7 fully recovered their vision 15 days after initial treatment. Cases 1 and 4 presented at two months with NR and NRB respectively from the contralateral eye to the affected one, but with less clinical severity compared to that of their debut in the months of August and September. Both have received the same treatment with satisfactory therapeutic results.

Patients 2, 3 and 4 maintain their normal vision in both eyes, without variations in their biannual clinical evaluation. Patient 5 currently has optic atrophy, so his case is considered a therapeutic failure with total loss of the VA of the affected eye (RE). Patient 7 has not attended the 6-month evolution check-up.

\section{Discussion}

In the present series of cases, the frequency of presentation of NO is unusual, both in the experience of the professionals of the Neurophthalmology department of the HHA 15 and that of other consulted authors [1-12].

The hypothesis of the authors of this research is based on the increase in the so-called Arboviruses in the analyzed period, according to the personal communication of the HHA Epidemiology Specialist, but could not provide official statistical data. There was a special situation in 2018, which remains in the current Covid-19 pandemic.

In Cuba, studies on the prevalence and incidence of NO have not been carried out, but based on the evidence from clinical practice, the number of cases received in the evaluated period corresponds approximately to the totality of those diagnosed and treated in the period 2017.

The age coincides with several authors who have published small series of cases with NO in one or both eyes, with a predominance of young people, under 50 years of age [13-18] and differs from others who report averages of ages ranging between 42 and 62 years [12-18].

According to the literature reviewed [1-11]. in these patients, typical NO is ruled out due to the absence of periocular pain, the age of presentation, and the lack of therapeutic response at one week in almost half of the cases ( $43 \%)$.

It is important to note that the unilateral NO observed in these patients is different from Epidemic Optic Neuropathy, which occurred in Cuba in the 1990s,19 with bilateral involvement in most cases, which improved rapidly (7-10 days) with vitamin treatment and protein-rich diet. The toxicnutritional-metabolic etiology was confirmed in all these cases.

Treatment with intravenous steroids and B vitamins was satisfactory in patients treated on the seventh day of evolution of NO. Several authors use this therapeutic scheme [1-11,1822]. although others prefer the oral route and local injection of steroids in cases with unilateral NO [16].
Most of the authors consulted raise the therapeutic effectiveness of corticosteroid therapy in these patients [1-1215,19] and also emphasize the importance of early treatment (less than 4 days after vision loss) to avoid irreversible damage to the axonal skeleton and the evolution to post-neuritis optic atrophy [9].

The results of 15 years of follow-up in the ONTT (Optic Neuritis Treatment Trial) 10 revealed a 50\% probability of developing MS.

In patient 5 of the present series, NMOSD was considered, due to the alterations that are evidenced in the study carried out. However, there is no dissemination of space, since the MRI of the cervical region is normal and there are no oligocloal bands in the study of the CSF. In addition, the absence of a response to steroids in this patient and the rapid evolution towards optic atrophy are characteristics of NMOSD, but only with the evolutionary follow-up and the determination of anti-aquaporin antibodies 4,3 will it be possible to define the definitive diagnosis of the same. . (Anti-aquaporin 4 antibodies are specific for NMOSD, they are not related to the epidemic genius of the period analyzed.

It is considered that in this case (5) the physiopathogenesis is more linked to vascular factors related to diabetes mellitus and hypertension, both uncontrolled, than to multiple sclerosis and / or NMOSD, which differs from the rest of the case series , in which these antecedents did not exist and if the previous clinical condition with all the clinical elements of viral disease, coming from a geographical area of the island (Ciénaga de Zapata) with an abundance of vectors such as mosquitoes.

The study and measurement by OCT of the GCIPL has become a biological marker that shows damage (still subclinical) of the optic nerve and the retina4,11. Pasol11 suggests that, if the disc edema has not reached the macula, the GCIPL analysis detects and predicts atrophy up to two months earlier than the information provided by the study of the retinal nerve fiber layer. $\mathrm{Xu} 17$ detected a sensitivity of $70 \%$ for this study in the detection and prognosis of visual recovery from NO.

The results of the present series coincide with the aforementioned and it is evidenced in cases 1, 4 and 5, where the involvement of GCIPL was associated with NO in the contralateral eye in the first two and with irreversible visual loss in the last.

In the studied casuistry, the effectiveness of the treatment of NO with steroids and B complex vitamins was conditioned by the evolution time with which the patients were diagnosed and treated. The aforementioned confirms the importance of early treatment, that is, as soon as the lack of vision occurs, to achieve satisfactory results, which is protocolized in the HHA, 15 and by most of the consulted authors, 6-14, 16-19 In addition, the usefulness of OCT in the visual diagnosis and prognosis of retinal and optic nerve disorders was evidenced, specifically the study of the GCIPL complex.

In the present series, it was not possible to perform specific 
studies (IgG, IgM) to confirm viral infection; We only rely on the referred clinical data, on the incidence of cases in a short period of time and on the publications of other authors $[13,14,16]$, with similar clinical-epidemiological data and serological confirmation. The foregoing constitutes a limitation. Specially designed studies are required to demonstrate this association.

\section{Conclusions}

An unusual increase in patients with unilateral optic neuritis was observed in a short period of time. The OCT revealed damage to the structures at the level of the retina and the optic nerve. The therapeutic effectiveness was conditioned by the time of evolution of the neuritis.

\section{References}

1. Soelberg K, Jarius S, Skejoe H, Engberg H, Mehlsen J, et al. (2017) A populationbased prospective study of optic neuritis. Mult Scler 23: 1893-1901. Link: https://bit.ly/3m1fxQ9

2. Gaier E, Boudreault K, Rizzo J, Falardeau J, Cestari D (2015) Atypical optic neuritis. Curr Neurol Neurosci Rep 15: 76. Link: https://bit.ly/3EVJSZ1

3. Hinson SR, Lennon VA, Pittock SJ (2016) Autoimmune AQP4 channelopathies and neuromyelitis optica spectrum disorders. Handb Clin Neurol 133: 377 403. Link: https://bit.ly/2XPweps

4. Petzold A (2017) Neuroprotection and visual function after optic neuritis. Curr Opin Neurol 30: 67-73. Link: https://bit.ly/3i7j12A

5. Toosy A, Mason D, Miller D (2014) Optic neuritis. Lancet Neurol 13: 83-99. Link: https://bit.ly/39HZeBW

6. Shindler K, Ventura E, Dutt M, Rostami A (2008) Inflammatory demyelination induces axonal injury and retinal ganglion cell apoptosis in experimental optic neuritis. Exp Eye Res 87: 208-213. Link: https://bit.ly/3EYoUJg

7. Zhu B, Moore G, Zwimpfer T, Kastrukoff L, Dyer J, et al. (1999) Axona cytoskeleton changes in experimental optic neuritis. Brain Res 824: 204-217. Link: https://bit.ly/2Zqdz46
8. Osinga E, Oosten B, Vries-Knoppert W, Petzold A (2017) Time is vision in recurrent optic neuritis. Brain Res 1673: 95-101. Link: https://bit.ly/3kJb5pV

9. Petzold A, Wong S, Plant GT (2016) Autoimmunity in visual loss. Handb Clin Neurol 133: 353-376. Link: https://bit.ly/2XRpvem

10. The clinical profile of optic neuritis (1991) Experience of the Optic Neuritis Treatment Trial. Optic Neuritis Study Group. Arch Ophthalmol 109: 1673-1678. Link: https://bit.ly/3zJz4th

11. Pasol J (2011) Neuro-ophthalmic disease and optical coherence tomography. Current Op Ophthalmol 22: 124-132. Link: https://bit.ly/3zHpJ51

12. Fuentes Pelier D, Hodelín Fuentes D, Penagos Payares M (2014) Caracterización de pacientes con neuritis óptica anterior en el Centro Oftalmológico de Santiago de Cuba. Medisan 18: 1688-1696. Link: https://bit.ly/3udeLmZ

13. Marrocos de Aragão R, Alexandre Barreira IL, Costa Lima LN, Portela Rabelo L, Alves Pereira FB (2019) Neurite óptica bilateral apósinfecção viral por dengue: relato de casos. Arq Bras Oftalmol 73: 175-178. Link: https://bit.ly/3o5vCae

14. Sanjay S, Wagle AM, Eong KGA (2019) Dengue Optic Neuropathy. J Am Acad Ophthalmol 116: 170. Link: https://bit.ly/3kHpBhD

15. Márquez Fernández M, Cáceres Toledo M, Cáceres Toledo $O$ (2018) Enfermedades adquiridas del nervio óptico. En: Manual de Prácticas Médicas del Hospital Clínico-Quirúrgico Hermanos Ameijeiras. 4ta. Ed. La Habana: Hospital Clínico Quirúrgico Hermanos Ameijeiras 1-15.

16. Yip VCH, Sanjay S, Koh YT (2012) Ophthalmic Complications of Dengue Fever: a Systematic Review. Ophthalmol Ther 1: 2. Link: https://bit.ly/3kKrrhU

17. Xu S, Kardon R, Leavitt J, Flanagan E, Pittock S, et al. (2019) Optical coherence tomography is highly sensitive in detecting prior optic neuritis. Neurology 92 : e527-e535. Link: https://bit.ly/3ugKOgT

18. Beltrán Saínz RI, Hernández Baguer R, Savón George LM (2019) Manifestaciones retinianas secundarias a Dengue. Reporte de caso. Rev Habanera Ciencias Méd 16: 420-426. Link: https://bit.ly/3CQkodS

19. González-Quevedo A, Santiesteban-Freixas R, Eells JT, Lima L, Sadun AA (2018) Cuban epidemic neuropathy: insights into the toxic-nutritional hypothesis through international collaboration. Medicc Rev 20: 27-31. Link: https://bit.ly/39DiLDE

\footnotetext{
Discover a bigger Impact and Visibility of your article publication with Peertechz Publications

Highlights

* Signatory publisher of ORCID

* Signatory Publisher of DORA (San Francisco Declaration on Research Assessment)

* Articles archived in worlds' renowned service providers such as Portico, CNKI, AGRIS, TDNet, Base (Bielefeld University Library), CrossRef, Scilit, J-Gate etc.

* Journals indexed in ICMJE, SHERPA/ROMEO, Google Scholar etc.

* OAI-PMH (Open Archives Initiative Protocol for Metadata Harvesting)

* Dedicated Editorial Board for every journa

* Accurate and rapid peer-review process

* Increased citations of published articles through promotions

* Reduced timeline for article publication

Submit your articles and experience a new surge in publication services (https://www.peertechz.com/submission).
} 